\title{
A commentary on TREAT: The trial of early aggressive drug therapy in juvenile idiopathic arthritis
}

\author{
Eileen Baildam
}

\begin{abstract}
Polyarticular juvenile idiopathic arthritis (JIA) is a category of JIA where multiple joints are affected by chronic inflammation, and where serious and lasting damage to joints is the expected natural history in untreated disease. There is evidence of response to disease-modifying antirheumatic and biologic drugs, but little evidence of permanent remission from any of the existing therapeutic trials. The TREAT trial by Wallace et al., recently published in Arthritis and Rheumatism, used a collaborative multicenter approach to studying early aggressive treatment of polyarticular JIA in an attempt to achieve full clinical inactive disease after 6 months of treatment. The study's main finding that the earlier in the disease course that treatment is started, the better the chance of disease control, has provided evidence that there is a 'window of opportunity' for treating JIA as there is in adult rheumatoid arthritis (RA). The study provides both a platform and an impetus for concentrating future treatment trials on early rather than established disease and investigating a standard of starting treatment within 10 to 12 weeks.
\end{abstract}

Keywords: Childhood arthritis, polyarticular juvenile arthritis, treatment

\section{Background}

The term juvenile idiopathic arthritis (JIA) is used to cover a group of conditions in childhood from infancy to the age of 17 where arthritis is the main feature and is truly idiopathic (that is, where no definite infective, malignant, hematological or other autoimmune cause is found for the arthritis). There are various subtypes defined in the JIA spectrum, agreed by expert consensus (International League of Associations for Rheumatology (ILAR) criteria) [1,2] to be as near to individual disease entities as possible, especially for the purpose of future research into more exact etiologies for these conditions.

Polyarticular JIA is defined as the JIA type where five or more joints are involved with either a rheumatoid factor-positive (on two consecutive tests) or a rheumatoid factor-negative further subdivision [1,2]. JIA is said to be polyarticular if at any time in the first 6 months from onset the cumulative number of involved joints reaches five. If this additive total effect only occurs after 6 months from onset then the type is changed from

Correspondence: Eileen.baildam@alderhey.nhsuk

Department of Paediatric Rheumatology, Alder Hey Children's Foundation NHS Trust, Liverpool, UK oligoarticular (up to four joints involved) to extended oligoarticular (five or more joints after 6 months). In addition, the JIA subtypes of systemic onset JIA and enthesitis related JIA, as well as psoriatic JIA, can also involve five or more joints. If the other associated defining features of any these particular groups are missing or overlooked, it is possible for a clinical case to be assigned to the incorrect group. Indeed, there may be some false divisions between the various subtypes if polyarticular arthritis is the main feature. However, there are still too few studies with large enough subgroups of patients with all the subtypes to know if the ILAR classification criteria for subtypes is truly clinically relevant from a therapeutic point of view in disease with polyarticular involvement. There is no single diagnostic test for any of the subtypes of JIA apart from a persistently raised rheumatoid factor level in the absence of connective tissues disorders.

The incidence of JIA is approximately 1:10,000, with a prevalence in the population of around 1:1,000 and about one-third of cases being polyarticular in nature $[3,4]$. This subtype may affect from five to most joints, can cause erosive disease, joint deformities with damage 
to growth plates, reduced mobility and general debility from chronic inflammation. It is associated with longterm disease activity into adult life in over $60 \%$ of cases. Treatment to achieve clinical remission is therefore vital, but the exact algorithm of care to achieve full remission has still not been established and there is considerable variation between centers based on clinical experience.

The role of methotrexate in the polyarticular subtype is secure after controlled trials in relatively large numbers of patients [5-7]. Biologic therapies including antitumor necrosis factor (TNF) blockers have been shown to improve disease activity, but all treatment studies seem to plateau with $75 \%$ to $85 \%$ of patients responding at significant response levels [8]. Steroids are used in different ways, with short-term intravenous courses of methylprednisolone or one-off intramuscular depot injections and/or multiple and repeated intra-articular injections being favored by some with others using more long-term regimes of low dose oral steroids [9-11]. For difficult unresponsive and damaging disease there are suggestions that Rituximab use may have an important role [12]. So far, complete and sustained clinical remission allowing for complete withdrawal of treatment is rarely reported, and yet this remains the longterm aim of all treatment attempts [13-16].

\section{The TREAT trial: main findings and strengths of the study design}

There have been no studies in JIA designed to investigate an initial aggressive approach to treatment with an aim of early complete disease remission, although many clinicians individualize treatments in an effort to achieve this. The TREAT trial [17] compared subcutaneous methotrexate at $0.5 \mathrm{mg} / \mathrm{kg} /$ week to a maximum of 40 mg plus two placebos with the same methotrexate regime plus subcutaneous etanercept $0.8 \mathrm{mg} / \mathrm{kg} /$ week (maximum $50 \mathrm{mg}$ ) and oral prednisolone $0.5 \mathrm{mg} / \mathrm{kg} /$ day (maximum $60 \mathrm{mg}$ ) tapered to $0 \mathrm{mg}$ by 17 weeks.

The ambitious primary outcome was set as clinical inactive disease [18] at 6 months with clinical remission on medication within 12 months of treatment also assessed (defined as a continuous 6 months of clinically inactive disease while receiving medication).

The strength of this study was that it attempted to use the 'window of opportunity' approach for long-lasting disease control from aggressive initial treatment [13]. Rather than simply looking for improvement using the usual American College of Rheumatology (ACR) Paediatric 70 response rates ( $70 \%$ improvement) the much more stringent primary outcome of clinically inactive disease was used. Assessment of two active treatments versus two concurrent placebos was also a strength, as it involved analyzing a treatment algorithm rather than looking at a single drug effect.

The main finding of the study was that after 12 months clinical remission on treatment was achieved in significantly more patients in the intensive treatment group than in the placebo and methotrexate group $(P=$ 0.0534).

Potentially the most important finding of the study was that the shorter the disease duration was at baseline, the more likely it was that clinically inactive disease would be achieved by 6 months. For each month sooner after disease onset the aggressive treatment was begun, the more likely it was that clinical remission at 6 months would be achieved, and this was to a factor of 1.324 per month earlier. This finding does support the very important suggestion of a 'window of opportunity' for easier and more long-lasting disease control [13].

\section{Limitations of the TREAT trial}

There were disappointingly small numbers of patients achieving clinical remission on treatment by 12 months with $9 / 42(21 \%)$ in the full treatment arm and 3/43 (7\%) in the methotrexate and double placebo arm, suggesting that although this difference was statistically significant the treatment regime itself is unlikely to be the breakthrough in terms of the majority of patients that we are seeking. However, these patients had very severe disease and a large proportion (33\% to $40 \%$ ) had rheumatoid factor positivity.

The randomization process did allocate more severe patients to the placebo arm in terms of more active joints and a significantly higher erythrocyte sedimentation rate (ESR) in the placebo arm, but this should really have served to accentuate the effect of the full treatment regime. This study demonstrated how effective injected weekly methotrexate can be given early in the disease course.

The relatively large numbers of patients discontinuing complex studies such as this provides a warning to investigators to include larger numbers of patients than the strict power calculations allow in order that the final numbers in each group remain meaningful. Larger numbers also allow for more subanalyses to be carried out in the explanation of results.

It is possible that once-weekly etanercept is not as effective as twice-weekly etanercept in the initial phases of treatment and that oral prednisolone is not as effective as intramuscular, intravenous or multiple intraarticular routes of steroid administration. The definition of clinically inactive disease may have been too stringent in this study with the 2011 consensus for provisional 
criteria for definitions containing a few amendments that may be more realistic [19].

\section{Conclusions}

These findings support the need to continue the search for a rapid initial remission-inducing regime, and yet the protocol studied does not appear to be that exact regime. The findings that the earlier treatment is started the more likely that clinical remission on treatment will be achieved at 12 months is a fundamental one in encouraging clinicians and healthcare providers to continue to be open to new regimes, rather than enshrining accepted protocols such as National Institute for Health and Clinical Excellence (NICE)-agreed protocols in practice forever.

The need now is for a study of 'tight control' until clinical inactive disease is achieved using a personalized approach, with addition of therapies with short interval reviews until the patient is fully under control (as has been shown in adult rheumatoid arthritis), and then to describe what these regimes require [19-22]. The results of the TREAT trial are worrying enough to justify more substantial treatments such as a trial of rituximab on first diagnosis of polyarticular JIA rather than after failure of more widely used treatments.

\section{Author information}

EB is Consultant Paediatric Rheumatologist at Alder Hey Children's Foundation NHS Trust and Deputy Chair of the Clinical Studies Group in Paediatric Rheumatology, a part of the UK Medicines for Children Research Network and Arthritis Research UK

\section{Competing interests}

The author declares that they have no competing interests.

Received: 24 May 2012 Accepted: 13 June 2012 Published: 13 June 2012

\section{References}

1. Petty RE, Southwood TR, Manners P, Baum J, Glass DN, Goldenberg J: International League of Associations for Rheumatology classification of juvenile idiopathic arthritis; second revision. Edmonton, 2001. J Rheumatol 2004, 31:390-392.

2. Ravelli A, Martina A: Juvenile idiopathic arthritis. Lancet 2007, 369:767-778.

3. Symmons DP, Jones M, Osborne J, Sills J, Southwood TR, Woo P: Pediatric rheumatology in the United Kingdom: data from the British Pediatric Rheumatology Group National Diagnostic Register. J Rheumatol 1996, 23:1975-1980.

4. Gortmaker SL, Sappenfield W: Chronic childhood disorders: prevalence and impact. Pediatr Clin North Am 1984, 31:390-392.

5. Giannini EH, Brewer EJ, Kuzmina N, Shaikov A, Maximov A, Vorontsov I, Fink CW, Newman AJ, Cassidy JT, Zemel LS: Methotrexate in resistant juvenile rheumatoid arthritis. Results of the U.S.A.-U.S.S.R. double-blind, placebo-controlled trial. The Pediatric Rheumatology Collaborative Study Group and The Cooperative Children's Study Group. N Engl J Med 1992, 326:1043-1049.

6. Woo P, Southwood TR, Prieur AM, Doré CJ, Grainger J, David J, Ryder C, Hasson N, Hall A, Lemelle I: Randomized, placebo-controlled, crossover trial of low-dose oral methotrexate in children with extended oligoarticular or systemic arthritis. Arthritis Rheum 2000, 43:1849-1857.

7. Ruperto N, Murray KJ, Gerloni V, Wulffraat N, de Oliveira SK, Falcini F, Dolezalova P, Alessio M, Burgos-Vargas R, Corona F, Vesely R, Foster H, Davidson J, Zulian F, Asplin L, Baildam E, Consuegra JG, Ozdogan H, Saurenmann R, Joos R, Pistorio A, Woo P, Martini A, Pediatric Rheumatology International Trials Organization: A randomized trial of parenteral methotrexate comparing an intermediate dose with a higher dose in children with juvenile idiopathic arthritis who failed to respond to standard doses of methotrexate. Arthritis Rheum 2004, 50:2191-2201.

8. Beresford MW, Baildam EM: New advances in the management of juvenile idiopathic arthritis 2: the era of biologicals. Arch Dis Child Ed Pract 2009, 94:151-156.

9. Cleary AG, Murphy HD, Davidson JE: Intra-articular corticosteroid injections in juvenile idiopathic arthritis. Arch Dis Child 2003, 88:192-196.

10. Marti $P$, Molinari L, Bolt IB, Seger R, Saurenmann RK: Factors influencing the efficacy of intra-articular steroid injections in patients with juvenile idiopathic arthritis. Eur J Pediatr 2008, 167:425-430.

11. Hyrich KL, Lal SD, Foster HE, Thornton J, Adib N, Baildam A, GardnerMedwin, Wedderburn LR, Chieng A, Davidson J, Thomson W: Disease activity and disability in children with juvenile idiopathic arthritis one year following presentation to paediatric rheumatology. Results from the Childhood Arthritis Prospective Study. Rheumatology (Oxford) 2010, 49:116-122.

12. Alexeeva El, Valieva SI, Bzarova TM, Semikina EL, Isaeva KB, Lisitsyn AO, Denisova RV, Chistyakova EG: Efficacy and safety of repeat courses of rituximab treatment in patients with severe refractory juvenile idiopathic arthritis. Clin Rheumatol 2011, 30:1163-1172.

13. Resman-Targoff BH, Cicero MP: Aggressive treatment of early rheumatoid arthritis:recognising the window of opportunity and treating to target goals. Am J Manag Care 2010, 16(Suppl):S249-258.

14. Davies K, Cleary G, Foster H, Hutchinson E, Baildam E, British Society of Paediatric and Adolescent Rheumatology: BSPAR Standards of Care for children and young people with juvenile idiopathic arthritis. Rheumatology (Oxford) 2010, 49:1406-1408.

15. Raza K, Stack R, Kumar K, Filer A, Detert J, Bastian H, Burmester GR, Sidiropoulos P, Kteniadaki E, Repa A, Saxne T, Turesson C, Mann H, Vencovsky J, Catrina A, Chatzidionysiou A, Hensvold A, RantapaaDahlqvist S, Binder A, Machold K, Kwiakowska B, Ciurea A, Tamborrini G, Kyburz D, Buckley CD: Delays in assessment of patients with rheumatoid arthritis: variations across Europe. Ann Rheum Dis 2011, 70:1822-1825.

16. Kennedy T, McCabe C, Struthers G, Sinclair H, Chakravaty K, Bax D, Shipley M, Abernethy R, Palferman T, Hull R, The British Society for Rheumatology Standards, Guidelines and Audit Working Group (SGAWG): BSR guidelines on standards of care for persons with rheumatoid arthritis. Rheumatology (Oxford) 2005, 44:553-556.

17. Wallace CA, Giannini EH, Spalding SJ, Hashkes PJ, O'Neil KM, Zeft AS, Szer IS, Ringold S, Brunner HI, Schanberg LE, Sundel RP, Milojevic D, Punaro MG, Chira P, Gottlieb BS, Higgins GC, Ilowite NT, Kimura Y, Hamilton S, Johnson A, Huang B, Lovell DJ, The Childhood Arthritis Rheumatology Research Alliance (CARRA): Trial of early aggressive therapy in polyarticular juvenile idiopathic arthritis. Arthritis Rheum 2012, 64:2012-2021.

18. Wallace CA, Ruperto N, Giannini E: Preliminary criteria for clinical remission for select categories of juvenile idiopathic arthritis. $J$ Rheumatol 2004, 31:2290-2294.

19. Wallace CA, Giannini E, Huang B, Itert L, Ruperto N, The Childhood Arthritis and Rheumatology Research Alliance (CARRA), the Pediatric Rheumatology Colloborative Study Group (PRCSG) and the Paediatric Rheumatology International Trials Organisation (PRINTO): American college of Rheumatology provisional criteria for defining clinical inactive disease in select categories of juvenile idiopathic arthritis. Arthritis Care Res (Hoboken) 2011, 63:929-936.

20. Bakker MF, Jacobs JWG, Verstappen SMM, Bijlsma JWJ: Tight control in the treatment of rheumatoid arthritis:efficacy and feasibility. Ann Rheum Dis 2007, 66(Suppl iii):iii56-iii60.

21. Schipper LG, Vermeer M, Kuper HH, Hoekstra MO, Haagsma CJ, Broeder AA, Riel PV, Fransen J, van de Laar MA: A tight control treatment strategy aiming for remission in early rheumatoid arthritis is more effective than usual care treatment in daily clinical practice: a study of two cohorts in 
the Dutch Rheumatoid Arthritis Monitoring registry. Ann Rheum Dis 2012, 71:845-850.

22. Boers M: The COBRA trial 20 years later. Clin Exp Rheumatol 2011, 29(Suppl):S46-51.

Pre-publication history

The pre-publication history for this paper can be accessed here: http://www.biomedcentral.com/1741-7015/10/59/prepub

doi:10.1186/1741-7015-10-59

Cite this article as: Baildam: A commentary on TREAT: The trial of early aggressive drug therapy in juvenile idiopathic arthritis. BMC Medicine 2012 10:59.

Submit your next manuscript to BioMed Central and take full advantage of:

- Convenient online submission

- Thorough peer review

- No space constraints or color figure charges

- Immediate publication on acceptance

- Inclusion in PubMed, CAS, Scopus and Google Scholar

- Research which is freely available for redistribution

Submit your manuscript at www.biomedcentral.com/submit 